\title{
TRAF Domain
}

National Cancer Institute

\section{Source}

National Cancer Institute. TRAF Domain. NCI Thesaurus. Code C13439.

The TRAF domain is the portion of TRAF family adaptor proteins which bind to TNF receptor cytoplasmic domain. It is the C-terminal homology region of 230 amino acids of signal-transducing proteins associated with members of the TNFR superfamily. This domain is involved in a variety of specific protein-protein interactions. 